\title{
Flow Shear Induced Compton Scattering of Electron Drift Instability
}

\author{
T. S. Hahm \\ Princeton Plasma Physics Laboratory, Princeton University \\ Princeton, N.J.
}

\begin{abstract}
Plasma flow shear effects on nonlinear saturation of electron drift waves are analyzed in the weak turbulence regime. Flow shear can enhance ion Compton scattering of long wavelength electron drift waves not only by modifying the beat wave-ion resonance condition, but also via the radial dependence of linear susceptibility. A nonlinear dispersion relation is obtained as a solution of the radially nonlocal nonlinear eigenmode equation. At nonlinear saturation, the spectral intensity of the fluctuations scales with flow shear as $(\partial \mathrm{V} \varphi / \partial \mathrm{r})^{-2}$ in addition to the linear dependence on the linear growth rate.
\end{abstract}

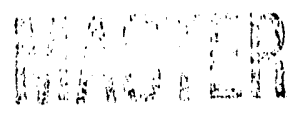




\section{Introduction}

The effect of flow shear on tokamak fluctuation and transport has recently become a topic of considerable theoretical interest. Several experiments ${ }^{1-4}$ suggest that sheared flow at the edge may play a crucial role in quenching edge fluctuation 5,6 and in the $\mathrm{L}$ to $\mathrm{H}$ transition observed in H-mode discharges. ${ }^{6-9}$ Furthermore, sheared toroidal rotation observed in the tokamak core region 10,11 during neutral beam heating has motivated a number of investigations on possible anomalous toroidal momentum loss mechanisms, ${ }^{12,13}$ such as the ion temperature gradient driven mode and the trapped electron instability. Most theoretical studies of these electrostatic microinstabilities in the presence of sheared plasma flow have focused on the linear stability properties. ${ }^{14-17}$

Results from a recent study on a simple model of electron drift wave turbulence ${ }^{18}$ have indicated a significant modification of nonlinear coupling due to plasma flow shear. In this study, attention was focused on the strong turbulence regime. It was pointed out that plasma flow shear introduces a new feature in the renormalized propagator, affecting nonlinear wave-particle interaction. ${ }^{19,18}$ However, the weak turbulence regime has not been explored in detail.

In this paper, we investigate toroidal flow shear effects on the nonlinear saturation of electron drift waves in the weak turbulence regime. The strongly dissipative trapped electron mode (DTEM) with $\omega_{\text {be }}>v_{\text {eff }}>\omega, \omega_{* e}>\omega_{\text {de }}$ is considered for illustration. ${ }^{20}$ Here, $\omega$ is the mode frequency, $\omega_{* e}=C_{s} \rho_{s} k_{\theta} / L_{n}$ is the electron diamagnetic drift frequency, $\omega_{t e}=v_{T e} / q R$ and $\omega_{\mathrm{be}}=\varepsilon^{1 / 2} v_{\mathrm{Te}} / \mathrm{qR}$ are the electron transit and bounce frequencies, and $\omega_{\mathrm{de}}$ is the orbit-averaged trapped elertron precession drift frequency. 
Since this mode is dispersive in the linearly most unstable $\mathrm{k}_{\vartheta}$-range, a number of weak turbulence approaches have been attempted based upon the nonlinear wave-particle interactions. 21-24 The (dispersion-induced) ion Compton scattering, 25-27 which transfers fluctuation energy to longer poloidal wavelengths, has been found to be the dominant nonlinear mechanism. However, at the longer poloidal wavelength side of the spectrum where fluctuation energy tends to accumulate, the dispersion-induced ion Compton scattering becomes weaker. Plasma flow shear, however, can enhance the ion Compton scattering of moderately long wavelength electron drift waves not only by modifying the beat wave-ion resonance condition, 19,18 but also by introducing radial dependence into the linear susceptibility. 28 The focus of this paper is on this flow shear induced ion Compton scattering of moderately long wavelength drift waves.

The remainder of this paper is organized as follows. In Sec.II, a nonlinear eigenmode equation, which contains flow shear induced ion Compton scattering, is derived from the weak turbulence analysis of the nonlinear ion gyrokinetic equation. Here, the role of flow shear induced ion Compton scattering in introducing radial dependence in nonlinear coupling is discussed. The nonlinear dispersion relation is obtained as a solution of the nonlinear eigenmode equation in Sec. III. Finally, the implications of the principal results from the present studies are discussed in Sec. IV. 


\section{Flow Shear Induced Compton Scattering}

In this section, the procedure for deriving the nonlinear evolution equation of fluctuations associated with drift instabilities in the presence of flow shear is developed in the weak turbulence regime. Rather than dealing with the wave kinetic equation which describes the nonlinear evolution of the radial-mode-width-averaged fluctuation spectral intensity, we derive the nonlinear eigenmode equation. This nonlocal approach allows us to examine the radial dependence of the Compton scattering cross section and the radial structure of the fluctuations. The emphasis is on a new nonlinear mechanism, the flow shear induced ion Compton scattering. Since the focus of this paper is on this new nonlinear mechanism, we consider the strongly dissipative trapped electron mode where nonlinearities in the electron dynamics can be ignored. As shown in the previous studies, ${ }^{29-31}$ this simplification cannot be justified for the collisionless trapped electron mode

The theoretical model considered in this paper consists of the Boltzmann response for the untrapped electrons and the strongly dissipative trapped electron response which is characterized by the following formula. 20

$$
\delta n_{e} / n_{0}=(1-i \delta) l e \mid \Phi / T_{e}
$$

where $\delta=\varepsilon^{1 / 2} \omega_{* \mathrm{e}}\left(1-\left(\omega_{\mathrm{k}} / \omega_{* \mathrm{e}}\right)+3 \eta_{\mathrm{e}} / 2\right\} / \nu_{\mathrm{eff}}$

Ions are treated by the collisionless gyrokinetic equation. The relevant frequencies in the linear analysis are ordered as $\omega_{\mathrm{te}}>\omega_{\mathrm{be}}>v_{\text {eff }}>\omega, \omega_{* \mathrm{e}}>\omega_{\mathrm{de}}$, and $\omega, \omega_{* \mathrm{e}}>\omega_{\mathrm{di}}, \omega_{\mathrm{ti}}$. Here, $\omega_{\mathrm{ti}}$ 
$=v_{\mathrm{Ti}} / \mathrm{qR}$ is the ion transit frequency, the ion magnetic drift frequency is $\omega_{\mathrm{di}}$, and the orbit-averaged trapped electron precession drift frequency is $\omega_{\mathrm{de}}$.

The collisionless nonlinear gyrokinetic equation 28,32 for ions in sheared slab geometry is

$$
\left(\partial_{t}+\left(V_{o}+c_{\|} b\right) \cdot \nabla-B^{-1} \nabla \Phi \times b \cdot \nabla\right) F-(e / M)\left(b-B^{-1} b \times \nabla V_{o \|}\right) \cdot \nabla \Phi\left(\partial F / \partial c_{\|}\right)=0
$$

where $c_{\|}=v_{\|}-v_{o \|}$. The parallel shear flow drive term 33,12 is contained in the last term of Eq. (2). After defining $g=f_{i 1}+F_{m} e \phi / T_{i}$ and adopting the ordering of Frieman and Chen, ${ }^{32}$ we have

$$
\begin{aligned}
& -\mathrm{i}\left(\omega-\mathbf{k} \cdot \mathrm{V}_{0}-\mathrm{k}_{\vartheta} \times c_{\|} / \mathrm{L}_{\mathrm{s}}\right) \mathrm{g}+\mathrm{i} \tau\left[\omega-\mathbf{k} \cdot \mathrm{V}_{\mathrm{o}}-\omega_{* \mathrm{i}}\left(1+\left(\mathrm{u}^{2}-3\right) \eta_{\mathrm{i}} / 2\right\}+\mathrm{k}_{\vartheta} \mathrm{V}_{\mathrm{o} \|} \mathrm{c}_{\|} / \Omega_{\mathrm{i}} \mathrm{L}_{\mathrm{v}}\right] \Phi \mathrm{J}_{0} \mathrm{~F}_{\mathrm{m}} \\
& =\nabla \Phi \mathrm{J}_{0} \times \mathbf{b} \cdot \nabla \mathrm{g}
\end{aligned}
$$

where $\mathrm{g}$ is the nonadiabatic part of the perturbed distribution function; $\mathrm{F}_{\mathrm{m}}=$ $\mathrm{n}_{\mathrm{O}}\left(\mathrm{M}_{\mathrm{i}} / 2 \pi \mathrm{T}_{\mathrm{i}}\right)^{3 / 2} \exp \left(-\mathrm{u}^{2} / 2\right), \mathrm{u}^{2}=\mathrm{M}_{\mathrm{i}} \mathrm{v}^{2} / \mathrm{T}_{\mathrm{i}}, \mathrm{b}=\mathrm{B} / \mathrm{B} \mid, \Phi=\mathrm{e} \phi / \mathrm{T}_{\mathrm{e}}$, and $\phi$ is the electrostatic potential, and $\mathrm{J}_{0}\left(\mathrm{k}_{\perp} \rho_{\mathrm{i}}\right)$ is a Bessel function, $\tau=\mathrm{T}_{\mathrm{e}} / \mathrm{T}_{\mathrm{i}}$. In this paper, concentrating on core fluctuation, we consider only toroidal rotation for simplicity. Of course, $V_{0} \varphi$ has a finite component in the direction perpendicular to $\mathbf{B}$.

Starting from Eq. (3), we carry out the usual weak turbulence expansion 25 up to third order, to get the following nonlinear ion response. In the expansion, we have kept the only dominant "bare" contribution,

$$
g_{k}(3)=-\Sigma_{k^{\prime}}\left(C_{s} \rho_{s} k \times k^{\prime} \cdot b\right)^{2} L_{i k} L_{i k}\left(\chi^{(1)}{ }_{k}-\chi^{(1)} k^{\prime}\right\} J_{0}{ }^{2} J_{0}{ }^{2} F_{m}\left|\Phi_{k^{\prime}}\right|^{2} \Phi_{k}
$$


where the part of the linear response which leads to the linear susceptibility after velocity space integration is given by

$$
\left.\chi^{(1)}\right)_{k}=\tau\left[\omega-k \cdot V_{0}-\omega_{* i}\right] /\left(\omega-k \cdot V_{0}-k_{\vartheta} \times c_{/} / L_{s}\right)
$$

In this paper, we call this quantity the linear susceptibility. In Eq. (5), we have ignored ion temperature gradient and parallel shear flow modifications ${ }^{12,33}$ for simplicity, and we are keeping only the resonances from the (driven) beat mode particle interactions, $\mathrm{L}_{\mathrm{ik}}=\mathrm{i}$ $\left(\omega^{\prime \prime}-k^{\prime \prime} \cdot V_{0}\left(x^{\prime \prime}\right)-k_{\vartheta}{ }^{\prime \prime} x^{\prime \prime} c_{\|} / L_{s}\right)^{-1}$. Other possible wave-particle resonant interactions at $k$ or $k^{\prime}$ are neglected in the nonlinear response since only the high energy ions participate. Therefore, we use the following approximate formula in Eq. (4),

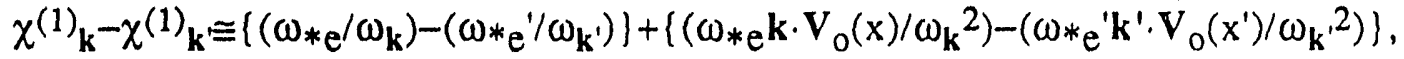

where $\omega_{\mathbf{k}}=\omega-\mathbf{k} \cdot \mathbf{V}_{0}$ and $\omega_{\mathbf{k}}{ }^{\prime}=\omega^{\prime}-\mathbf{k}^{\prime} \cdot \mathbf{V}_{\mathrm{o}}$ are the Doppler shifted frequencies at the reference rational surfaces, $\mathrm{x}$ and $\mathrm{x}^{\prime}$ measure the distance from the reference rational surfaces. The first term on the right hand side of Eq. (6) is the familiar term which is finite due to the dispersion of drift waves, and responsible for the transfer of fluctuation energy to lower $k_{\vartheta}$ modes (i.e., poloidal coupling). We call this process "dispersion-induced ion Compton scattering" in this paper. The second term originates from the radial dependence of the equilibrium flow, and we call this "flow shear induced ion Compton scattering." It is crucial to note that unlike the dispersion induced ion Compton scattering, this term remains finite even for $k_{\vartheta} \rho_{s} \rightarrow 0$, and 
causes the mode coupling in the radial direction. This is or.e of the reasons we have to consider radially nonlocal analysis in the context of the nonlinear eigenmode equation, rather than dealing with the radial-mode-width-averaged spectral intensity alone. In this paper, we concentrate on the flow shear induced ion Compton scattering which is dominant for the longer wavelength side of the electron drift wave spectrum. Here, we have not renormalized the propagator $\mathrm{L}_{\mathrm{ik}}$ " to include the broadening of the beat wave frequency caused by nonlinear effects. This weak turbulence approach limits the validity regime of the analysis to weak instability cases. The frequency broadening due to nonlinear effects, $\Delta \omega_{\mathrm{NL}}$, can be evaluated straightforwardly. ${ }^{30}$ In the present case, $\Delta \omega_{N L} \propto \Phi^{2}$ (rather than $\Delta \omega_{N L} \propto \Phi$, which is characteristic of strong turbulence). Therefore, the validity condition $\Delta \omega_{N L}<k_{\theta} w_{k} r$ $(\partial \mathrm{V} \varphi / \partial \mathrm{r}) / \mathrm{qR}$ leads approximately to $\gamma<\mathrm{k}_{\theta} \mathrm{w}_{\mathbf{k}} \mathrm{r}(\partial \mathrm{V} \varphi / \partial \mathrm{r}) / \mathrm{q} R$, where $\mathrm{w}_{\mathbf{k}}$ is the radial linear mode width. Using the approximate expression of the linear susceptibilities, we get

$$
\begin{aligned}
& \operatorname{Im} \int \mathrm{d}^{3} \mathrm{vJ}_{0} g_{k}(3) \\
& =\operatorname{Im} \sum_{k^{\prime}}\left(C_{s} \rho_{s} k \times k^{\prime} \cdot b\right)^{2}\left(\omega-k \cdot V_{c}\right)^{-1} \int_{d^{3}}{ }_{v}\left(\omega-k^{\prime \prime} \cdot V_{0}\left(x^{\prime \prime}\right)-k_{\vartheta} " x^{\prime \prime} c_{\|} / L_{S}\right)^{-1} \\
& {\left[\left\{\left(\omega_{*} e^{/ \omega_{k}}\right)-\left(\omega * e^{\left.\left.1 / \omega_{k^{\prime}}\right)\right\}+\left\{\left(\omega_{*} e^{k} \cdot V_{0}(x) / \omega_{k}{ }^{2}\right)-\left(\omega \omega_{e} k^{\prime} \cdot V_{0}\left(x^{\prime}\right) / \omega_{k^{\prime}}{ }^{2}\right)\right\}}\right]\right.\right.} \\
& \mathrm{J}_{0}^{2} \mathrm{~J}_{0}{ }^{2} \mathrm{~F}_{\mathrm{m}}\left|\Phi_{\mathrm{k}^{\prime}}\right| 2 \Phi_{\mathrm{k}}
\end{aligned}
$$

In analytically performing the mode summation for various nonlinear interaction channels (i.e., the summation over all the background modes which satisfy $k^{\prime}=k-k^{\prime \prime}$ ), we adopt the following continuum approximation which takes the effect of magnetic shear on the distribution of mode rational surface into account. 26 By changing the independent variables from $n^{\prime}, m^{\prime}$ to $k_{\phi^{\prime}}$ and $x^{\prime}, \Sigma_{k^{\prime}} \cong \int d n^{\prime} d m^{\prime}=\int\left|\partial\left(n^{\prime}, m^{\prime}\right) / \partial\left(k_{\phi^{\prime}}, x^{\prime}\right)\right| d k_{\phi}{ }^{\prime} d x^{\prime}=$ 
$R^{2}(d q / d r) \int d k_{\phi^{\prime}}\left|k_{\phi^{\prime}} \iint d x^{\prime} \equiv(r S / q) \int d k_{\theta^{\prime}}\right| k_{\theta^{\prime}} \mid \int d x^{\prime}$, where $S=d l n q / d l n r$ is the magnetic shear. Consequently, the right hand side can be evaluated explicitly at a radial position $x$ after using an appropriate radially nonlocal expressions, $\left(k \times k^{\prime} \cdot b\right)^{2}\left|\Phi_{k^{\prime}}\right|^{2} \Phi_{k} \cong k_{\theta}{ }^{2}\left|\partial \Phi_{k^{\prime}} / \partial x^{\prime}\right| 2 \Phi_{k}$. Here, we consider a radially long wavelength test mode $\mathbf{k}$ and radially short wavelength background modes $k^{\prime}$ which can be treated by continuum approximation. Therefore, they satisfy $k_{\theta}{ }^{2} k_{r}{ }^{2}$ $\ll \mathrm{k}_{\theta}{ }^{2} \mathrm{k}_{\mathrm{r}}^{\prime}$. The radial structure of the short wavelength background mode is given by $\left|\Phi_{\mathrm{k}}^{\prime}\right|^{2}=$ $I\left(k_{\theta}^{\prime}\right) \exp \left(-\left(x^{\prime}-\Delta_{k}{ }^{\prime}\right) / w_{k}{ }^{2}\right)$, where the radial shift $\Delta_{k}$ and the radial mode width are given by the straightforward linear analyses in the weak flow shear regime $\left(V_{s}<s\right)$ where the effective potential becomes radially shifted quadratic well,

$$
\begin{aligned}
& \Delta_{k}{ }^{\prime}=-V_{s} \rho_{s} / 2 s^{2}, \\
& w_{k}{ }^{\prime}=s^{-1 / 2} \rho_{s} .
\end{aligned}
$$

We note that higher radial harmonics of electron drift waves are more strongly damped and subdominant to the gaussian-shaped fundamental radial harmonics considered here. For analytical progress, the beat wave-ion resonance is approximated by $\delta\left(\omega "-k^{\prime \prime} \cdot V_{0}\left(x^{\prime \prime}\right)\right)$. Then, Eq. (7) simplifies to

$$
\begin{aligned}
& \operatorname{Im} \iint_{d} 3_{v} J_{0} g_{k}(3)=\pi\left(C_{s} \rho_{s}\right)^{2}\left(\omega-k \cdot V_{0}\right)^{-1}(r S / q) \int d k_{\theta^{\prime}} \mid k_{\theta^{\prime}} \iint d x^{\prime} k_{\theta}{ }^{2}\left\{\left(x^{\prime}-\Delta_{k}\right)^{2} / w_{k}{ }^{4}\right\} I\left(k_{\theta}^{\prime}\right)
\end{aligned}
$$

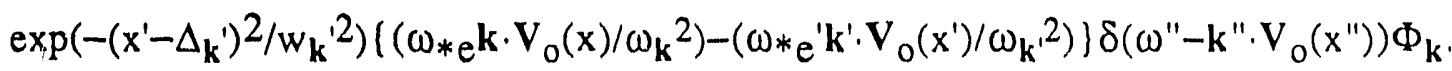

Here, we have only kept the flow shear induced ion Compton scattering. For this nonlinear process, the dominant contribution comes from the close interactions between modes with similar frequencies and similar $\mathbf{k}$ 's. This is because the distant interaction which involves high-k' contributions is reduced by the gyro-orbit average factor $\mathrm{J}_{0}{ }^{2}$. For close interactions 
between low $\mathbf{k}$ modes, we can approximate the Bessel functions by 1 . We then perform the $\mathrm{k}_{\theta}{ }^{\prime}$-integration using the following differential approximation for close interactions, ${ }^{25} \mathrm{I}\left(\mathrm{k}_{\theta}^{\prime}\right) \cong$ $I\left(k_{\theta}\right)+\left(k_{\theta}^{\prime}-k_{\theta}\right) \partial I\left(k_{\theta}\right) / \partial k_{\theta}$, to get

$$
\operatorname{Im} \int_{\mathrm{d}}{ }^{3} \mathrm{vJ}_{0} g_{k}(3)=\left\{N_{A}+N_{B} \omega_{*} e^{\prime}\left(\omega_{*} \omega_{0}{ }^{\prime \prime}-W_{\perp} x\right)+N_{C} \omega_{*} e^{2} /\left(\omega_{*} e \omega_{0} "-W_{\perp} x\right)^{2}\right\} \Phi
$$

where the radial dependence of nonlinear response is indicated by defining

$$
\begin{aligned}
& \mathrm{N}_{\mathrm{A}}=\pi^{3 / 2} \mathrm{C}_{\mathrm{s}} \rho_{\mathrm{s}} \mathrm{L}_{\mathrm{n}}\left(\mathrm{k}_{\theta}{ }^{3 / 2} \omega_{\mathbf{k}} \mathrm{w}_{\mathbf{k}}\right)(\mathrm{rS} / \mathrm{q})\left\{\mathrm{I}\left(\mathrm{k}_{\theta}\right)+\mathrm{k}_{\theta} \partial \mathrm{I}\left(\mathrm{k}_{\theta}\right) / \partial \mathrm{k}_{\theta}\right\} \text {, } \\
& \mathrm{N}_{\mathrm{B}} \omega_{\mathrm{He}_{\mathrm{e}}}=-\pi^{3 / 2} \mathrm{C}_{\mathrm{s}} \rho_{\mathrm{s}} \mathrm{L}_{\mathrm{n}}\left(\mathrm{k}_{\theta}{ }^{3} / 2 \omega_{\mathrm{k}} \mathrm{w}_{\mathrm{k}}\right)(\mathrm{rS} / \mathrm{q}) \mathrm{W}_{\perp}\left(\mathrm{x}_{\mathrm{v}}-\Delta_{\mathrm{k}}\right)\left\{\mathrm{I}\left(\mathrm{k}_{\theta}\right)+2 \mathrm{k}_{\theta} \partial \mathrm{I}\left(\mathrm{k}_{\theta}\right) / \partial \mathrm{k}_{\theta}\right\} \text {, } \\
& \mathrm{N}_{C} \omega_{*} e^{2}=\pi^{3 / 2} \mathrm{C}_{\mathrm{S}} \rho_{\mathrm{S}} \mathrm{L}_{n}\left(\mathrm{k}_{\theta}{ }^{3 / 2} \omega_{\mathrm{k}} \mathrm{w}_{\mathrm{k}}\right)(\mathrm{rS} / \mathrm{q}) \mathrm{W}_{\perp}{ }^{2}\left\{\left(\mathrm{x}_{\mathrm{v}}-\Delta_{\mathrm{k}}\right)^{2}+3 \mathrm{w}_{\mathrm{k}}{ }^{2 / 4}\right\} \mathrm{k}_{\theta} \partial \mathrm{I}\left(\mathrm{k}_{\theta}\right) / \partial \mathrm{k}_{\theta} \text {. }
\end{aligned}
$$

$\omega_{0}{ }^{\prime \prime} \omega_{*_{e}}=k_{\vartheta} \partial \omega_{k} / \partial k_{\vartheta}$ is smaller than $\omega_{k}$ due to finite $k_{\vartheta} \rho_{s}, W_{\perp}=k \cdot \partial V_{\alpha} / \partial r$ measures the perpendicular flow shear, $x_{v}=\omega_{0} "(\omega) e_{e} / W_{\perp}$.

Finally with Eq. (9), the quasineutrality condition $\delta n_{e} / n_{0}=\delta n_{i}(1) / n_{0}+\delta n_{i}(3) / n_{0}$ yields the following nonlinear eigenmode equation in terms of dimensionless variables.

$\partial^{2} \Phi / \partial^{2} \mathrm{x}=\left[-1-\mathrm{b}_{\mathrm{s}}+\mathrm{i} \delta+1 /\left(\omega_{0}-\mathrm{V}_{\mathrm{s}} \mathrm{x}\right)+\mathrm{s}^{2} \mathrm{x}^{2} /\left(\omega_{0}-\mathrm{V}_{\mathrm{s}} \mathrm{x}\right)^{2}\right] \Phi+\mathrm{i} \operatorname{Im} \int_{\mathrm{d}}{ }^{3} \mathrm{vJ}_{0} g_{\mathrm{k}}(3)$

where $b_{s}=\left(k_{\vartheta} \rho_{s}\right)^{2}, s=S L_{n} / q R . \omega_{o}=\omega_{k}$ is the Dopper shifted eigenfrequency of 'test mode, $V_{s}=L_{n} W_{\perp} / k_{\theta} C_{s}$, $x$ has been normalized to $\rho_{s}$. We note that $2 . e \int d^{3} v_{0} g_{k}(3)$ shifts the real frequency by an order of $\Phi^{2}(\ll 1)$ and therefore can be ignored consistently with the weak turbulence ordering. 25 


\section{Nonlinear Eigenmode Analysis}

In the preceding section, we have derived a nonlinear eigenmode equation. In this section, we solve that equation to obtain the fluctuation amplitude and its radial dependence at nonlinear saturation. The third and fourth terms on the right hand side of Eq. (10) describe the convection of the ion density and the sound wave contribution respectively with the radial dependence coming from the Doppler shift of the test mode frequency. To obtain the nonlinear dispersion relation in a closed form, we modify the linear response slightly in the following way.

$$
\partial^{2} \Phi / \partial^{2} x=\left[-1-b_{s}+i \delta+\omega_{o} " / \omega_{o}\left(\omega_{o} "-V_{s} x\right)+s^{2} x^{2} /\left(\omega_{o} "-V_{s} x\right)^{2}\right] \Phi+i \operatorname{Im} \int d^{3} v_{0} g_{k}(3)
$$

The fourth term in the modified linear response still agrees with the corresponding term in Eq. (10) at small $\times$ (i.e., $\mathbf{E} \times \mathbf{B}$ convection of mean density), meanwhile the fifth term in the modified linear response still agrees with the corresponding term in Eq. (10) at large x. We have made this particular choice since the large- $x$ asymptotics of the sound term has been found to be crucial in determining the radial mode structure in the linear regime. . hen, Eq. (11) can be put into the following Whittaker's form ${ }^{34}$ by defining $Y=2 i \alpha\left(\omega_{0}{ }^{\prime \prime}-V_{s} x\right) / V_{s}$, with $\alpha=\left[s^{2}\right.$ $\left.+V_{s}^{2}\left\{-1-b_{S}+i\left(\delta+N_{A}\right)\right\}\right]^{1 / 2}$.

$$
\partial^{2} \Phi / \partial^{2} Y+\left\{-1 / 4+\kappa / Y+\left(1 / 4-\mu^{2}\right) / Y^{2}\right\} \Phi=0
$$


where

$$
\begin{aligned}
& \kappa=i\left(2\left(s / V_{s}\right)^{2} \omega_{0}{ }^{\prime \prime}-\omega_{0}{ }^{\prime \prime} / \omega_{0}-i N_{B}\right\} / 2 \alpha \\
& \mu^{2}=1 / 4-\left\{\left(s / V_{s}\right)^{2} \omega_{0}{ }^{\prime 2}+i N_{C}\right\} / V_{s}{ }^{2}
\end{aligned}
$$

In choosing the right solution of Eq. (12), the $\mathrm{i}\left(\delta+\mathrm{N}_{\mathrm{A}}\right)$ contribution to the definition of $\alpha$ should not be taken literally, since both the nonadiabatic electron response and the nonlinear ion response should decay as the distance from the reference mode rational surface increases. Then, for weak flow shear case with $s>V_{s}$, we have to choose a solution $W_{\kappa, \mu}(Y)$ with $\kappa$ and $\mu$ satisfying the following dispersion relation for the dominant fundamental radial harmonics,

$$
\kappa(1-\kappa)=1 / 4-\mu^{2}
$$

The asymptotic behavior of $W_{\kappa, \mu}(Y)$ for large $x$ is given by

$$
W_{\kappa, \mu}(Y) \approx Y^{K} \exp (-Y / 2)
$$

showing algebraic decay, since $\alpha^{2}>0$, and $\operatorname{Re}(\kappa)<0$, for $\operatorname{Im} \omega_{0}>0$. For weak flow shear, the nonlinear dispersion relation, Eq. (13) simplifies to

$$
1 / \omega_{0}=1+b_{S}-i\left(\delta+N_{A}\right)+i\left(\alpha-N_{B}\right) / \omega_{0} "-i N_{C} / \omega_{0}{ }^{\prime \prime 2}
$$

At nonlinear saturation, Im $\omega_{0} \rightarrow 0$, therefore, the imaginary part of Eq. (14) yields 


$$
\delta-\alpha / \omega_{0} "=-N_{A}-N_{B} / \omega_{0}{ }^{\prime \prime}-N_{C} / \omega_{0}{ }^{\prime \prime}
$$

This is a first-order inhomogeneous differential equation for the spectral intensity $I\left(k_{\vartheta}\right)$,

$$
\partial \mathrm{I}\left(\mathrm{k}_{\theta}\right) / \partial \mathrm{k}_{\theta}+\mathrm{T}\left(\mathrm{k}_{\theta}\right) \mathrm{I}\left(\mathrm{k}_{\theta}\right)=-\mathrm{S}\left(\mathrm{k}_{\theta}\right) / \mathrm{U}\left(\mathrm{k}_{\theta}\right)
$$

where

$$
\begin{aligned}
& T\left(k_{\theta}\right)=\Delta_{k} / x_{v} k_{\vartheta}\left\{\left(\Delta_{k} / x_{v}\right)^{2}+3 w_{k}{ }^{2} / 4 x_{v}{ }^{2}\right\} \\
& S\left(k_{\theta}\right)=\delta-\alpha / \omega_{0} " \\
& U\left(k_{\theta}\right)=\pi^{3 / 2} C_{s} \rho_{s} L_{n}\left(k_{\theta}{ }^{4} / 2 \omega_{k} w_{k}\right)(r S / q)\left\{\left(\Delta_{k} / x_{v}\right)^{2}+3 w_{k} 2 / 4 x_{v}{ }^{2}\right\}
\end{aligned}
$$

Equation (16) can be written in a more tractable form of

$$
\mathrm{U}\left(\mathrm{k}_{\theta}\right) \exp \left(-\mathrm{R}\left(\mathrm{k}_{\theta}\right)\right) \partial\left\{\mathrm{I}\left(\mathrm{k}_{\theta}\right) \exp \left(\mathrm{R}\left(\mathrm{k}_{\theta}\right)\right)\right\} / \partial \mathrm{k}_{\theta}=-\mathrm{S}\left(\mathrm{k}_{\theta}\right)
$$

with $R\left(k_{\theta}\right)=\int d k_{\theta} T\left(k_{\theta}\right)$.

Here, $U\left(k_{\theta}\right) \exp \left(-R\left(k_{\theta}\right)\right)$ plays the role of convective velocity in $k_{\theta}$ space, while $S\left(k_{\theta}\right)$, being the linear drive (damping), plays the role of a source (sink). The positive definiteness of $U\left(k_{\theta}\right)$ indicates that flow shear induced ion Compton scattering transfers fluctuation energy to lower $k_{\theta}$ region. After integiating Eq. (17) from $k_{\theta}$ to $k_{H}$ ( high- $k_{\theta}$ where dispersion-induced ion Compton scattering becomes significant) we get 


$$
\mathrm{I}\left(\mathrm{k}_{\theta}\right) \exp \left(\mathrm{R}\left(\mathrm{k}_{\theta}\right)\right)=\mathrm{I}\left(\mathrm{k}_{\mathrm{H}}\right) \exp \left(\mathrm{R}\left(\mathrm{k}_{\mathrm{H}}\right)\right)+\int_{\mathrm{k}_{\theta}}^{\mathrm{k}_{H}} \mathrm{dk}_{\theta} \mathrm{S}\left(\mathrm{k}_{\theta}\right) \exp \left(\mathrm{R}\left(\mathrm{k}_{\theta}\right)\right) / \mathrm{U}\left(\mathrm{k}_{\theta}\right)
$$

We take $\omega_{0}{ }^{\prime \prime} \cong 1$ such that

$$
\mathrm{S}\left(\mathrm{k}_{\theta}\right)=\left(\delta\left(\mathrm{k}_{\mathrm{H}}\right) / \mathrm{k}_{\mathrm{H}}\right) \mathrm{k}_{\theta}-\alpha
$$

Then, the linear instability occurs for $k_{\theta}>k_{L}=k_{H} \alpha / \delta\left(k_{H}\right)$. With this simplified $S\left(k_{\theta}\right)$, Eq.(18) reduces to

$$
\mathrm{I}\left(\mathrm{k}_{\theta}\right)=\left(\delta\left(\mathrm{k}_{\mathrm{H}}\right) / \mathrm{k}_{\mathrm{H}} \mathrm{U}_{0}\left(1+\mathrm{T}_{0}\right)\right) \mathrm{k}_{\theta}^{-1}-\left(\mathrm{s} / \mathrm{U}_{0}\left(2+\mathrm{T}_{0}\right)\right) \mathrm{k}_{\theta}^{-2}
$$

where $\mathrm{k}_{\theta} \ll \mathrm{k}_{\mathrm{H}}$ has been used to ignore subdominant surface terms, and the following quantities are $\mathrm{k}_{\theta}$-independent within the approximations we have mentioned,

$$
\begin{aligned}
& T_{0}=-\Delta_{k} / x_{v}\left\{\left(\Delta_{k} / x_{v}\right)^{2}+3 w_{k}{ }^{2} / 4 x_{v}{ }^{2}\right\}, \\
& U_{0}=\pi^{3 / 2}\left(L_{n}{ }^{2} r S / 2 w_{k} q\right)\left\{\left(\Delta_{k} / x_{v}\right)^{2}+3 w_{k}{ }^{2} / 4 x_{v}{ }^{2}\right\} .
\end{aligned}
$$

We note that the fluctuation exists ( $\mathrm{I}\left(\mathrm{k}_{\theta}\right)>0$ ) even for $\mathrm{k}_{\theta}$ lower than $\mathrm{k}_{\mathrm{L}}$ (the low- $\mathrm{k}_{\theta}$ cut-off given by the linear marginal stability ). Physically, flow shear induced ion Compton scattering transfers fluctuations towards lower $k_{\theta}$ causing over-spill beyond the linear cut-off. Equation (20) predicts the nonlinear low $-k_{\theta}$ cut-off at $\left(1+\mathrm{T}_{0}\right) \mathrm{k}_{\mathrm{L}} /\left(2+\mathrm{T}_{0}\right)<\mathrm{k}_{\mathrm{L}}$.

For $\left(1+T_{0}\right) k_{L} /\left(2+T_{0}\right) \ll<k_{\theta}$, the first term of Eq. (20) dominates and we can write Eq. (20) in a more illuminating form, 


$$
I\left(k_{\theta}\right)=F_{s} j\left(k_{H}\right)\left(1 / k_{H} k_{\theta} L_{n}^{2}\right)
$$

where $F_{s}=\left(4 / \pi^{3 / 2}\right) S^{1 / 2} q^{3 / 2}\left(R / L_{n}\right)^{1 / 2}\left(\rho_{s} C_{s}{ }^{2} / r^{3}\right)(\partial V \varphi / \partial r)^{-2}$ for $s<1$. We note that the saturated amplitude of tie fluctuations is smaller than the usual mixing length estimates $I\left(k_{\theta}\right) \cong$ $1 / k_{\theta}{ }^{2} L_{n}{ }^{2}$. The reduction contains a form factor $F_{s}$ due to flow shear, in addition to the linear dependence on the normalized growth rate $\delta$ which is typical of a weak turbulence analysis result. 25 The spectral shape exhibits a $\mathrm{k}_{\theta}$-dependence which is flater than the prediction ${ }^{23}$ based upon dispersion induced ion Compton scattering which is applicable to the shorter wavelength region. 


\section{Conclusions}

In this paper, plasma flow shear effects on nonlinear saturation of electron drift waves have been analyzed in the weak turbulence regime. The strongly dissipative trapped electron instability has been considered in a sheared slab geometry with a focus on wave-ion nonlinear interaction. It has been shown that flow shear can enhance ion Compton scattering of moderately long wavelength (weakly dispersive) electron drift waves not only by modifying the beat wave-ion resonance condition, but also via the radial dependence of linear susceptibility. The weak turbulence expansion of the nonlinear gyrokinetic equation leads to a nonlinear eigenmode equation which can be put into the familiar Whittaker's form. A nonlinear dispersion relation is obtained from a radially nonlocal eigenmode analysis. At nonlinear saturation, the spectral intensity of the fluctuations scales with flow shear as $(\partial \vee \varphi / \partial r)^{-2}$ in addtion to the linear dependence on the linenr growth rate.

\section{Acknowledgments}

The author would like to thank W. M. Tang, P. H. Diamond, F. L. Waelbroeck, N. Bretz, and M. Artun for useful discussions.

This work was supported by U.S. Department of Energy Contract No. DE-AC02-76-CHO-3073. 


\section{References}

1 R. J. Taylor, M. L. Brown, B. D. Fried, H. Grote, J. R. Liberati, G. J. Morales, P. Pribyl, D. Darrow, and M. Ono, Phys. Rev. Lett. 63, 2365 (1989).

2 R. J. Groebner, K. H. Burrell, and R. P. Seraydian, Phys. Rev. Lett. 64, 3015 (1990).

3 Ch. P. Ritz, R. D. Bengston, S. J. Levinson, and E. J. Powers, Phys. Fluids 27, 2956 (1984).

4 K. Ida, S. Hidekuma, Y. Miura, T. Fujita, M. Mori, K. Hoshino, N. Suzuki, T. Yamauchi, and JFT-2M Group, Phys. Rev. Lett. 65, 1364 (1990).

5 T. Chiueh, P. W. Terry, P. H. Diamond, and J. E. Sedlak, Phys. Fluids 29, 231 (1986).

6 H. Biglari, P. H. Diamond, and P. W. Terry, Phys. Fluids B2, 1 (1989).

7 K. C. Shaing and E. C. Crume, Jr., Phys. Rev. Lett. 63, 2369 (1989).

8 S.-I. Itoh and K. Itoh, Nucl. Fusion 29, 1031 (1989).

9 A. B. Hassam, T. M. Antonsen, Jr., A. M. Dimits, J. F. Drake, P. N. Guzdar, Y. T. Lau, C. S. Liu, K. C. Shaing, P. J. Christenson, W. A. Houlberg, and R. D. Hazeltine, Plasma Physics and Controlled Nuclear Fusion Research 1990, Proceedings of the 13th International Conference, IAEA-CN-33/D-4-11, Washington DC, USA ( IAEA, Vienna )(1991)

10 S. Scott, P. Diamond, R. Fonck, R. Goldston, R. Howell, K. Iaenig, G. Schilling, E. Synakowski, M. Zarnstorff, C. Bush, E. Fredrickson, K. Hill, A. Janos, D. Mansfield, D. Owens, H. Park, G. Pautasso, A. Ramsey, J. Schivell, G. Tait, W. Tang, and G. Taylor, Phys. Rev. Lett. 64, 531 (1990).

11 K. H. Burrell, R. J. Groebner, T. S. Kurki-Suonio, T. N. Carlstrom, R. R. Dominguez, 
P. Gohil, R. A. Jong, H. Matsumoto, J. M. Lohr, T. W. Petrie, G. D. Porter, G. T. Sager, H. E. St. John, D. P. Schissel, S. M. Wolfe, and the DIII-D Research Group, Plasma Physics and Controlled Nuclear Fusion Research 1990, Proceedings of the 13th International Conference, IAEA-CN-53/A-2-3, Washington DC, USA (IAEA, Vienna $)(1991)$

12 N. Mattor and P. H. Diamond, Phys. Fluids 31, 1180 (1988).

13 T. S. Hahm and W. M. Tang, in Proceedings of the Workshop of the US-Japan Joint Institute for Fusion Theory Program on Structures in Confined Plasmas ( National Institute of Fusion Science, Nagoya, Japan, 1990), p.55

14 M. Artun and W. M. Tang, to be published in Phys. Fluids B.

15 X. H. Wang and P. H. Diamond, to be published in Phys. Fluids B.

16 S. Hamaguchi and W. Horton, to be published in Phys. Fluids B.

17 F. L. Waelbroeck, T. M. Antonsen, Jr., P. N. Guzdar, and A. B. Hassam, University of Maryland Laboratory for Plasma Research Preprint 92-011, November 91.

18 B. A. Carreras, K. Sidikman, P. H. Diamond, P. W. Terry, and L. Garcia, Submitted to Phys. Fluids B (1992).

19 P. H. Diamond, private communications (1990).

20 C. S. Liu, M. N. Rosenbluth, and W. M. Tang, Phys. Fluids 19, 1040 (1976).

21 A. Rogister and G. Hasselberg, Phys. Fluids 26, 1467 (1983).

22 P. L. Similon and P. H. Diamond, Phys. Fluids 27, 916 (1984).

23 F. Y. Gang, P. H. Diamond, and M. N. Rosenbluth, Phys. Fluids B 3, 68 (1991).

24 T. S. Hahm, Phys. Fluids B 3, 1445 (1991).

25 R. Z. Sagdeev and A. A. Galeev, in Nonlinear Plasma Theory, edited by T. M. O'Neil 
and D. L. Book (Benjamin, New York, 1969).

26 J. A. Krommes, Phys. Fluids 23, 736 (1980).

27 P. H. Diamond and M. N. Rosenbluth, Phys. Fluids 24, 1641 (1981).

28 T. S. Hahm, "Weak Turbulence Analysis of Drift Waves in the Presence of Plasma Flows" presented at US-Japan Workshop on Edge Turbulence and the Physics of H-mode (Madison, Wisconsin, 1991).

29 L. Chen, R. L. Berger, J. G. Lominadze, M. N. Rosenbluth, P. H. Rutherford, Phys. Rev: Lett. 39, 754 (1977).

30 P. H. Diamond, P. L. Similon, P. W. Terry, W. Horton, S. M. Mahajan, J. D. Meiss, M. N. Rosenbluth, K. Swartz, T. Tajima, R. D. Hazeltine, and D. W. Ross, in Plasma Physics and Controlled Nuclear Fusion Research 1982 (IAEA, Vienna, 1982), Vol. I, p. 259.

31 T. S. Hahm and W. M. Tang, Phys. Fluids B 3, 989 (1991).

32 E. A. Frieman and L. Chen, Phys. Fluids 25, 502 (1982).

33 P. J. Catto, M. N. Rosenbluth, and C. S. Liu, Phys. Fluids 16, 1719 (1973).

34 M. Abramowitz and I. A. Stegun, Handbook of Mathmatical Functions (Dover, New York, 1972). 


\section{EXTERNAL DISTRIBUTION IN ADDITION TO UC-420}

Dr. F. Peoloni, Univ. of Wollongong, AUSTRALIA

Prot. M.H. Brommen, Univ. of Syonoy, AUSTRALLA

Plasma Psosearch Lob., Austrilen Nat. Univ., AUSTRALLA

Prof. I.A. Jones, Finders Univ, AUSTRALIA

Prof. F. Cap, Inst for Theoretical Phycios, AUSTRIA

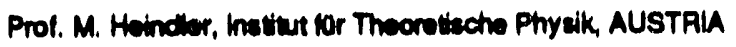

Prof. M. Goosecen, Aetronomiech InattuU, BELGIUM

Ecob Roy do Mintuirs, Leb. do Phy. Plasmma, BELGIUM

Commicaion-Europeen, DG. XIL-Fution Proo., BELGIUM

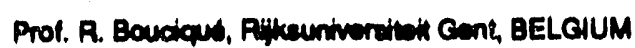

Dr. P.H. Sukencka, Instuto Fivion, BRUZIL

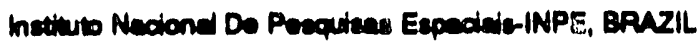

Documents Oriven, Alomic Energy of Ceneda Lod., CANADA

Dr. M.P. Bechyned, MPB Technologios, Inc., CANADA

Dr. H.M. Skeregard, Univ. of Sackatchemen, CANADA

Prot. J. Tolotmein, Univ, of Montreal, CANADA

Frot. S.F. Sreaniveaen, Univ. of Colpory, CANADA

Prof, T.W. Johneton, INRS-Energib, CANADA

Dr. R. Bovion, Centre canadien de husion magnstouse, CANADA

Dr. C.R. James, Univ. of Aberta, CANAOA

Dr. P. Lutice, Komenaktho Unhwerdita, CZECHOSLOVAKIA

The Lbrarten, Cuham Luboratory, ENGLAND

Libray, R31, Ruthertord Appletion Leboratory, ENGLAND

Mrs. S.A. Hutchineon, JET Lborary, ENGLAND

Dr. S.C. Shema, Univ, of South Pecific, FWI ISLANDS

P. Mutonen, Univ. of Heleintl, FINLAND

Prof. M.N. Bunasec, Ecols Potyluchniqus, ,FRANCE

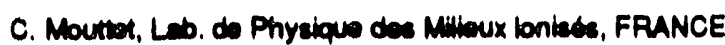

J. Radat, CENCADAPACHE - Bat 506, FRANCE

Prof. E. Economow, Univ, of Crew, GREECE

Ms. C. Rinn, Univ, of loamina, GREECE

Dr. T. Mued, Acadermy Bibliogrephic Ser., HONG KONG

Preprint Librery, Hungarian Academy of Sod., HUNGARY

Dr. B. Descupta, Saha inst. of Nucloer Ptycios, INDIA

Dr. P. Kaw, Inat. for Pleama Research, INDIA

Dr. P. Rosenew, lered inst. of Technology, ISPAEL.

Lborarien, Inbernadiond Cemer for Theo Physics, ITALY

Miss C. Do Pab, Associazione EURATOMENEA, ITALY

Dr. G. Groswo, lattuto di Fisican del Plasma, ITALY

Prof. G. Rostenoni, latius Gas loniezed Dat Cnr, ITALY

Dr. H. Yonewo, Tochibe Aas a Devel Conbr, JAPAN
Prof. I. Kawakemi, Hroshima Univ., JAPAN

Prof. K. Niahikewe, Hiroshima Univ., LAPAN

Orrector, Jepen Alomic Enorgy Rescarch Inst, JAPAN

Prot. S. Itoh, Kyuathu Univ., JAPAN

Rosearch into. Ctr., Nationd Instit. for Fucion Science, JAPAN

Prot. S. Tenakn, Kyolo Univ., JAPAN

Libreny, Kyoto Univ., JAPAN

Prof. N. Inows, Univ, of Tokyo, LAPAN

Scoretany, Plama Saston, Eloctrobectnical Lab, JAPAN

5. Mori, Technical Advisor, MERM, LAPAN

Dr. O. Minded, Kumemoto lnat of Tectnology, JAPAN

J. Hyeor-Sook, Korea Alomic Energy Rescarch Inst, KOAEA

D.1. Choi, The Korea Adv. Inst of Sdi. Toch., KOREA

Prot. B.S. Liby, Univ, of Weikato, NEW ZEALAND

Inst of Phyrita, Chinese Acad SA PEOPLE'S REP. OF CHINA

Lbrery, inat of Plasma Phyelos, PEOPLE'S REP. OF CHINA

Teinghua Unw. Librery, PEOPLE'S REPUBLIC OF CHINA

Z. L, S.W. hat Phydacs, PEOPLE'S REPUBLIC OF OHINA

Prof. J.A.C. Cabrd, Instituto Superior Tecrico, PORTUGAL

Dr. O. Potrus, AL I cuza Univ., ROMania

Dr. J. of Viulers, Fusion Studies, AEC, S. AFRICA

Prot. M.A. Menomo, Univ, of Natal, S. AFAICA

Prof. D.E. Km, Pohiang hat, of Sod. \& Tech., SO. KOREA

Prot. C.I.E.M.A.T, Fusion Diviaion Library, SPAIN

Dr. L STrmo, Univ, of UMEA, SWEDEN

Librery, Royd inat of Tectinology, SWEDEN

Prot. H. Whotmeon, Chaimers Univ, of Tech., SWEDEN

Comre Phys. Des Plasmas, Ecole Polytach, SWITZERLAND

Blbliotheak, inst. Voor Plarma-Fyeica, THE NETHERLANDS

Asal. Prot. Dr. S. Cakir, Moddo East Tech. Univ., TURKEY

Dr. V.A. Gukhikh, Sd. Res. Inst. Electrophys.I Apparatus, USSR

Dr. D.D. Ayutov, Siberian Branch of Academy of Sal, USSR

Dr. G.A. Eliecerv, I.V. Kurchabov InBt, USSA

Librerien, The Ukr.SSR Acodemy of Sciances, USSR

Dr. LM. Kovrizhnykh, Inat. of Gonoral Physias, USSR

Kemforechungseanlege GmbH, Zentrablbllothek, W. GERMANY

Bibliothest, Inst. For Plasmatorechung, W. GERMANY

Prof. K. Schinder, Rutr-Univerdit Bechum, W. GERMANY

Dr. F. Weoner, (ASDEX), Max Planck-Inettiut, W. GERMANY

Librarion, Max-Planck-Inetiut, W. GERMANY

Prot, R.K. Jenov, Inst of Physica, YUGOSLAVIA 

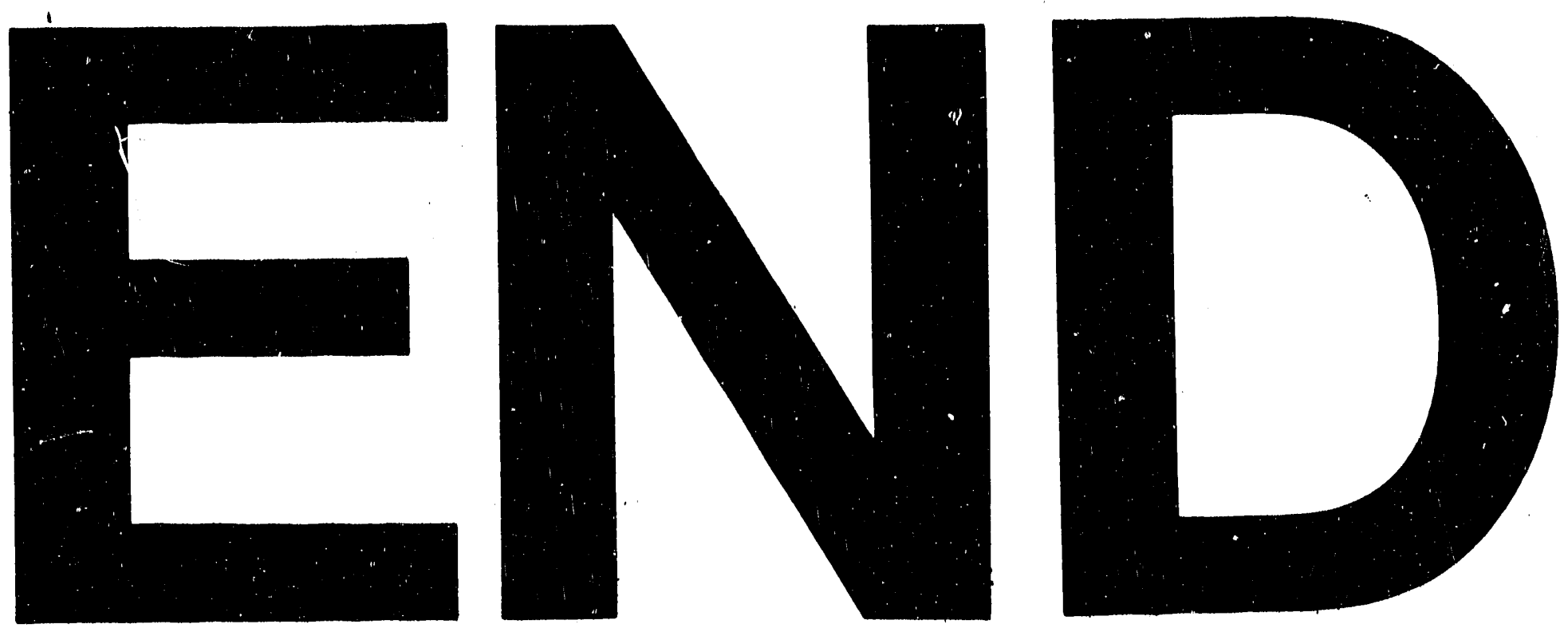

itom

$=-1$.
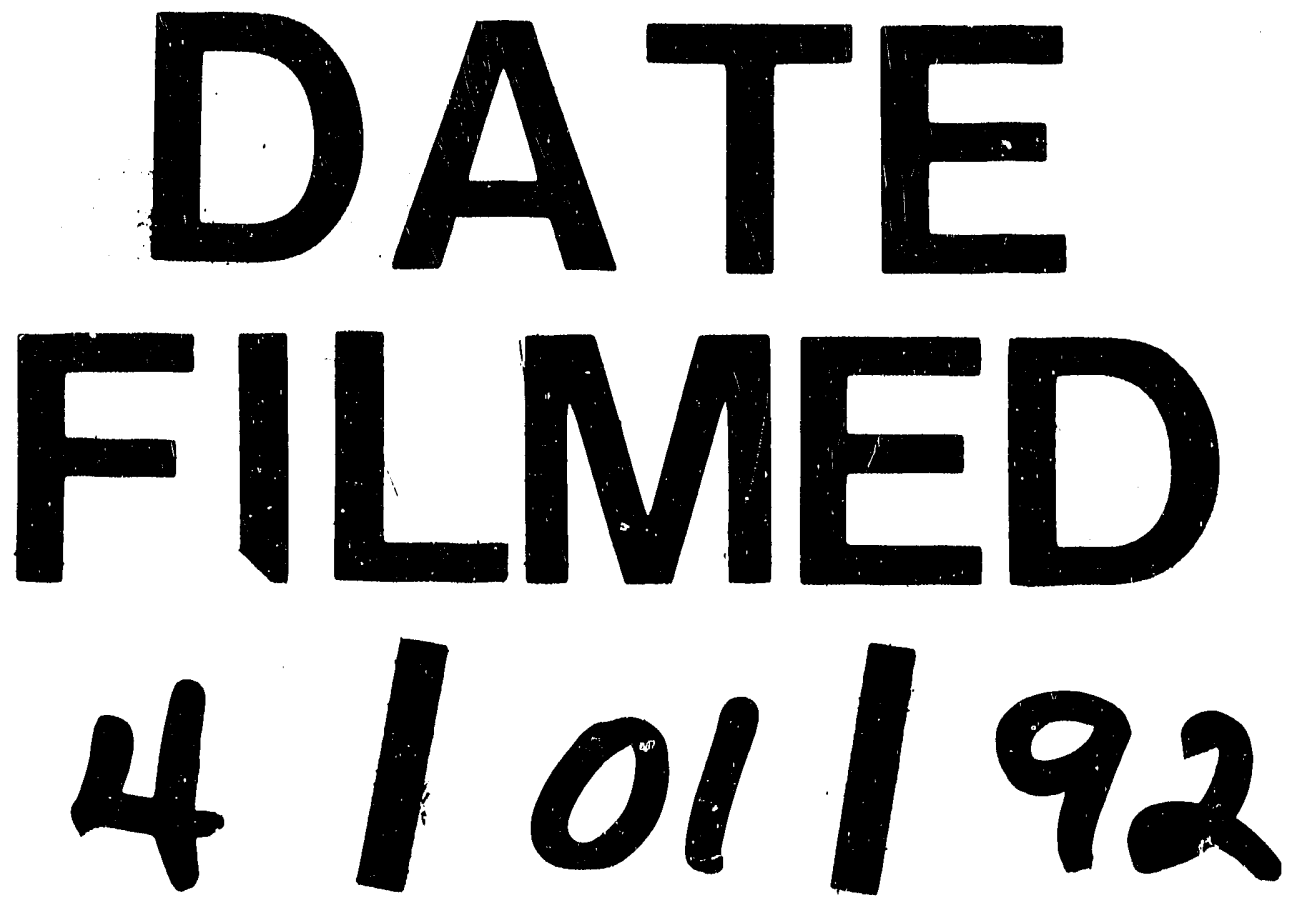

$I$ 
